\title{
PROOFS OF CERTAIN CONJECTURES OF VUKŠIĆ CONCERNING THE INEQUALITIES FOR MEANS
}

\author{
Chao-Ping Chen and Neven Elezović
}

Abstract. By using the asymptotic expansion method, Vukšić conjectured inequalities between Seiffert means and convex combinations of other means. In this paper, we prove certain conjectures given by Vukšić.

Mathematics subject classification (2010): 26E60, 26D05.

Keywords and phrases: Seiffert means, inequality.

\section{REFERENCES}

[1] M. Abramowitz ANd I. A. STEgun (Eds.), Handbook of Mathematical Functions with Formulas, Graphs, and Mathematical Tables, National Bureau of Standards, Applied Mathematics Series 55, 9th printing, Washington, 1970.

[2] G. D. Anderson, M. K. VAmAnamurthy AND M. Vuorinen, Inequalities for quasiconformal mappings in space, Pacific J. Math. 160 (1993), 1-18.

[3] G. D. Anderson, S.-L. Qiu, M. K. Vamanamurthy and M. Vuorinen, Generalized elliptic integral and modular equations, Pacific J. Math. 192 (2000), 1-37.

[4] T. Burić, N. Elezović, Asymptotic expansion of Arithmetic-Geometric mean, J. Math. Inequal. 9, 4 (2015), 1181-1190.

[5] Y. M. ChU, Y. F. QIU, M. K. WANG AND G. D. WANG, The optimal convex combination bounds of arithmetic and harmonic means for the Seiffert's mean, J. Inequal. Appl. 2010, Article ID 436457, 7 pages.

[6] Y. M. ChU, M. K. WANG AND W. M. Gong, Two sharp double inequalities for Seiffert mean, J. Inequal. Appl. 2011, 44, 7 pages.

[7] Y. M. ChU, C. Zong AND G. D. WANG, Optimal convex combination bounds of Seiffert and geometric means for the arithmetic mean, J. Math. Inequal. 5 (2011), 429-434.

[8] A. Cuyt, V. B. Petersen, B. Verdonk, H. WaAdeland and W. B. Jones, Handbook of Continued Fractions for Special Functions, Springer, New York, 2008.

[9] N. Elezović, Asymptotic inequalities and comparison of classical means, J. Math. Inequal. 9, 1 (2015), 177-196.

[10] N. Elezović, Asymptotic expansions of gamma and related functions, binomial coefficients, inequalities and means, J. Math. Inequal. 9, 4 (2015), 1001-1054.

[11] N. Elezović AND L. VuKŠIĆ, Asymptotic expansions of bivariate classical means and related inequalities, J. Math. Inequal. 8, 4 (2014), 707-724.

[12] N. ElEZOVIĆ AND L. VUKŠIĆ, Neuman-Sandor means, asymptotic expansions and related inequalities, J. Math. Inequal. 9, 4 (2015), 1337-1348.

[13] N. Elezović, L. MinoKović, Asymptotic behaviour of power means, Math. Inequal. Appl. 19, 4 (2016), 1399-1412.

[14] S.-Q. GAO, H.-Y. GAO AND W.-Y. SHI, Optimal convex combination bounds of the centroidal and harmonic means for the Seiffert mean, Int. J. Pure Appl. Math. 70 (2011), 701-709.

[15] H. LiU AND X. J. Meng, The optimal convex combination bounds for Seiffert's mean, J. Inequal. Appl. 2011, Art. ID 686834, 9 pages.

[16] H.-J. SeIFFERT, Problem 887, Nieuw Arch. Wiskunde, 11 (1993), 176. 
[17] H.-J. SEIFFERT, Aufgabe $\beta 16$, Wurzel, 29 (1995), 221-222.

[18] L. VUKŠIĆ, Seiffert means, asymptotic expansions and inequalities, Rad Hrvat. Akad. Znan. Umjet. Mat. Znan. 19 (2015), 129-142.

[19] A. WiTKOWS KI, Interpolations of Scwab-Borchardt mean, Math. Ineq. Appl. 16, 1 (2013), 193-206. 